\title{
Left Ventricular Function in Experimental
}

\section{Aorto-Caval Fistula with \\ Circulatory Congestion and Fluid Retention}

\author{
Roger R. Taylor, James W. Covell, and John Ross, JR. \\ From the Cardiology Branch, National Heart Institute, Bethesda, Maryland 20014
}

A в STRACT The mechanical properties of left ventricular contraction were described in terms of tension, velocity, length, and time in closed-chest, sedated dogs in which a large aorto-caval fistula had resulted in circulatory congestion, and the results were compared with those in normal dogs. Instantaneous contractile element velocity was calculated from left ventricular pressure and its first derivative during isovolumic left ventricular contractions produced by sudden balloon occlusion of the ascending aorta during diastole. A range of ventricular end-diastolic volumes was induced and heart rate was controlled at 150 beats $/ \mathrm{min}$. Wall tension (stress) was derived from ventricular pressure and volume, the latter being obtained from the pressure-volume relation of the passive ventricle. Extrapolated velocity at zero tension, $\mathrm{V}_{\text {max }}$, averaged $3.0 \mathrm{circ} / \mathrm{sec}$ in the normal dogs and $2.9 \mathrm{circ} / \mathrm{sec}$ in the seven dogs with an aortocaval fistula and fluid retention; in only one of these seven animals was $\mathrm{V}_{\max }$ below the lower limit of normal of $2.7 \mathrm{circ} / \mathrm{sec}$. Isovolumic tension $\left(\mathrm{P}_{\mathrm{o}}\right)$ in dogs with aorto-caval fistulas tended to be slightly greater than normal at low ventricular filling pressures, and there was no difference in $\mathrm{P}_{\mathrm{o}}$ between the two groups of animals at high ventricular filling pressures. Time to peak pressure averaged $151 \pm 6$ (SE) msec (normal 139 \pm 3 ). Left ventricular weight averaged $6.32 \pm 0.23$

Dr. Taylor is a Fellow of the National Heart Foundation of Australia and a Visiting Scientist, National Heart Institute, Bethesda, Md. 20014.

Received for publication 16 November 1967 and in revised form 12 January 1968. $\mathrm{g} / \mathrm{kg}$ of initial body weight (normal $5.25 \pm 0.56$ $\mathrm{g} / \mathrm{kg})(P<0.001)$, which reflected moderate ventricular hypertrophy, and ventricular internal volume at a given filling pressure was increased proportionally. Therefore, the ventricular contractile state usually was normal in the dog with a large aorto-caval fistula, and it is proposed that mechanisms for fluid retention that results in circulatory congestion were activated because of the large hemodynamic burden despite normal myocardial contractile properties.

\section{INTRODUCTION}

The general hemodynamic manifestations of a large systemic arteriovenous fistula have been well documented. In man the cardiac output, heart rate, and right atrial pressure are elevated, arterial pulse pressure is increased $(1-4)$, and the blood volume is expanded (5). Similar effects have been observed in the dog with an experimentally induced fistula (6-10), and a reduction in peripheral blood flow (7) and renal blood flow (10) also has been observed. In addition, maximum cardiac output, attainable by transfusion, may be greater in dogs with an arteriovenous shunt than in normal dogs, whereas the maximum stroke work is less (8). However, little information is available concerning the functional state of the ventricular myocardium in the presence of a large systemic arteriovenous fistula. Accordingly, in the present study, left ventricular tensionvelocity relations were measured in closed-chest sedated dogs with a large aorto-caval fistula and 
these were compared with those obtained in a group of normal dogs studied previously (11). We found that the contractile state of the left ventricle usually is normal in the dogs with a large aorto-caval fistula, despite marked elevation of left ventricular end-diastolic pressure, ascites, and edema.

\section{METHODS}

Mongrel dogs weighing between 16.4 and $23.6 \mathrm{~kg}$ were prepared before study as described previously (11). In brief, a median sternotomy was performed under pentobarbital anesthesia, the left lateral aspect of the pericardium was opened from apex to base and its lower free edge was sutured to the left chest wall to facilitate later percutaneous needle puncture of the left ventricle. The pericardium was left widely open. A $\frac{1}{2}$-inch band of Teflon tape was placed around the ascending aorta to provide support for balloon inflations. Electrodes were then sutured to the right atrial appendage, the ends of the lead wires implanted subcutaneously, and the chest closed with drainage. The fifteen dogs constituting the normal control group were those described previously (11). In the group of nine experimental dogs, 2 wk after the initial operation, a side-to-side, infrarenal, aorta-caval anastomosis $11-16 \mathrm{~mm}$ long and $5-7 \mathrm{~mm}$ in diameter was constructed, and these animals were studied after a further period that averaged 40 (29-49) days. Because these dogs usually were not studied until evidence of gross fluid retention appeared, a number of others died in pulmonary edema before study.

As previously (11), for the experimental procedure all animals were sedated with morphine $(3 \mathrm{mg} / \mathrm{kg})$, promazine $(1.5 \mathrm{mg} / \mathrm{kg})$, and promethazine $(1.5 \mathrm{mg} / \mathrm{kg})$ by intramuscular injection. Local anesthesia with xylocaine was used for all catheter insertions. Aortic pressure was measured through a polyethylene cannula passed into the thoracic aorta from the right femoral artery and left ventricular pressure was obtained through a short, stiff, polyethylene cannula (PE No. 220) that was inserted by direct percutaneous puncture with a No. 19 spinal needle as a trocar, and attached directly to a pressure transducer. Intraventricular pressure was referred to the level of the mid left ventricular (LV) cavity determined directly at the completion of each experiment. Intrapleural pressure (IPP) was measured through a self-retaining Foley catheter inserted through the right chest wall, and LV transmural pressure, which was used in all calculations, was obtained by subtraction of IPP from the measured LV pressure. The first derivative of LV pressure, $L V \mathrm{dp} / \mathrm{dt}$, was obtained with an analog differentiating circuit. ${ }^{1}$ All pressure were measured with Statham P23Db transducers and recorded with the electrocardiogram on a multichannel oscillograph 2 at a paper speed of $100 \mathrm{~mm} / \mathrm{sec}$. Cardiac

${ }^{1}$ Electronic Gear, Inc., Valley Stream, N. Y. Model No. 5602.

2 Sanborn Company, Waltham, Mass. Model No. 350. output was measured in duplicate in the normal dogs by superior vena caval injection of indocyanine green dye with aortic sampling; the standard deviation of cardiac output measurements by the method of paired measurements was $0.25 \mathrm{liter} / \mathrm{min}, 10.2 \%$ of the measurement. In the dogs with aorto-caval fistulas, dye was injected into the mid-left ventricle, via the catheter inserted by percutaneous puncture, to avoid distortion of the dilution curve by rapid recirculation. The standard deviation of the difference between paired measurements was 0.70 liter/ $\min , 10.0 \%$ of the measurement.

A rubber balloon mounted at the tip of a metal cannula was passed through the left carotid artery and placed in the ascending aorta just above the aortic valve (11). The balloon was rapidly inflated during diastole with 5-18 $\mathrm{ml}$ of saline by a power injector ${ }^{3}$ triggered from the electrocardiogram. Beats were analyzed only if they showed features characteristic of isovolumic contractions: a smooth LV pressure contour, a steady uninterrupted fall in $\mathrm{LV} \mathrm{dp} / \mathrm{dt}$ after its peak and a progressively falling aortic pressure. All isovolumic beats used for analysis were obtained during expiration.

The left ventricular end-diastolic volume (EDV), from which isovolumic beats originated, was derived from the transmural end-diastolic pressure (LVEDP) and the passive pressure-volume relation of the arrested ventricle was determined after sacrifice of the animal. The application of this method to the measurement of end-diastolic volume in the closed-chest animal has been described in detail in recent communications $(11,12)$. A study in progress in the closed-chest anesthetized dog indicates a good agreement between left ventricular volume measurements made by this method and those made using biplane cineangiography. 4

\section{Calculations}

The left ventricle was assumed to be a sphere, and an even distribution of left ventricular mass around the cavity, as well as an even distribution of stress across the ventricular wall, were assumed. Left ventricular wall tension was then calculated from the modified formula for a thin-walled sphere as: $\mathrm{T}=\mathrm{P} . \mathrm{r} / 2 \mathrm{~h} \mathrm{~g} / \mathrm{cm}^{2}$, where $\mathrm{P}=$ transmural ventricular pressure in $\mathrm{g} / \mathrm{cm}^{2} ; \mathrm{r}=$ internal radius in $\mathrm{cm}$; and $\mathrm{h}=$ wall thickness in $\mathrm{cm}$, as detailed elsewhere (11). The units of $\mathrm{T}, \mathrm{g} / \mathrm{cm}^{2}$, are those of stress; this value is considered to represent mean wall stress, and although no information is available on a true stress distribution across the wall, it is reasonable to assume that this value is close to the stress existing at the mid-wall. The term tension is used interchangeably with the term stress, and is expressed as total tension, end-diastolic tension, and the difference between these, active tension.

Contractile element velocity $\left(\mathrm{V}_{\mathrm{CE}}\right)$ during isovolumic

3 Cordis Power Injector, Cordis Corp., Miami, Fla.

4 A comparison of left ventricular volume measurements by biplane cineangiography and passive pressure-volume relations. Gault, J. H., R. R. Taylor, K. O'Brien, J. W. Covell, and J. Ross, Jr. In preparation. 
contractions was calculated as described previously (11). The rate of elongation of the series elastic, SE, (dl/dt) and $V_{C E}$ are assumed to be essentially equal in isovolumic contractions and

$$
\frac{\mathrm{dp} / \mathrm{dt}}{K \cdot \mathrm{p}}=\mathrm{dl} / \mathrm{dt}=\mathrm{V}_{\mathrm{CE}} \mathrm{cm} / \mathrm{cm} \text { per sec }
$$

(muscle lengths/sec, or circumferences/sec) (11). $K$ was taken to be 28 in all experiments in accord with values found in the dog's intact left ventricle $(13,14)$, and with the lowest value of $K$ found in cat isolated papillary muscle (15). In separate experiments, using a quick release method the series elasticity of cat papillary muscle was found to be unchanged by the induction of ventricular hypertrophy 5 supporting the use of the same elasticity constant in the two groups of animals.

During the experimental procedure, the rectal temperature of the dogs was between $36^{\circ}$ and $38^{\circ} \mathrm{C}$. Arterial oxygen saturation averaged $92 \%$ (range, $80-96 \%$ ) in the dogs with aorto-caval fistulas and $93 \%$ (range, 88-100\%)

5 Parmley, W. W., J. F. Spann, Jr., R. R. Taylor, and E. H. Sonnenblick. The Series elasticity of cardiac muscle in hyperthyroidism, ventricular hypertrophy, and heart failure. Submitted for publication. in the normal dogs. The arterial blood $\mathrm{pH}$ was 7.33 (range, 7.27-7.41) and 7.31 (range, 7.24-7.37) in the experimental and control animals, respectively, and arterial hematocrit values were $36 \%$ (range, $35-38 \%$ ) and $40 \%$ (range, 37-43\%), respectively. These studies showed no detectable differences between the arterial blood oxygen saturations and the blood $\mathrm{pH}$ values in the control and the experimental groups, although slight arterial desaturation existed in both. Control measurements were made with the dogs resting quietly in the supine position. After these measurements the dog's blood was exchanged with fresh blood obtained from donor dogs lightly anesthetized with sodium methohexital. ${ }^{6}$ The previously implanted right atrial electrode leads were attached to a stimulator ${ }^{7}$ and heart rate subsequently was maintained constant in each dog at average levels of $150.6 \pm 5.6$ (SD) in the normal animals and $152.4 \pm 6.6$ in the dogs with aorto-caval fistulas. Isovolumic contractions were then obtained over a wide range of transmural end-diastolic pressures obtained by infusion of the previously exchanged donor blood, and by bleeding.

6 Brevital sodium. Eli Lilly \& Co., Indianapolis, Ind.

7 American Electronic Laboratories, Inc., Model No. 104-A.
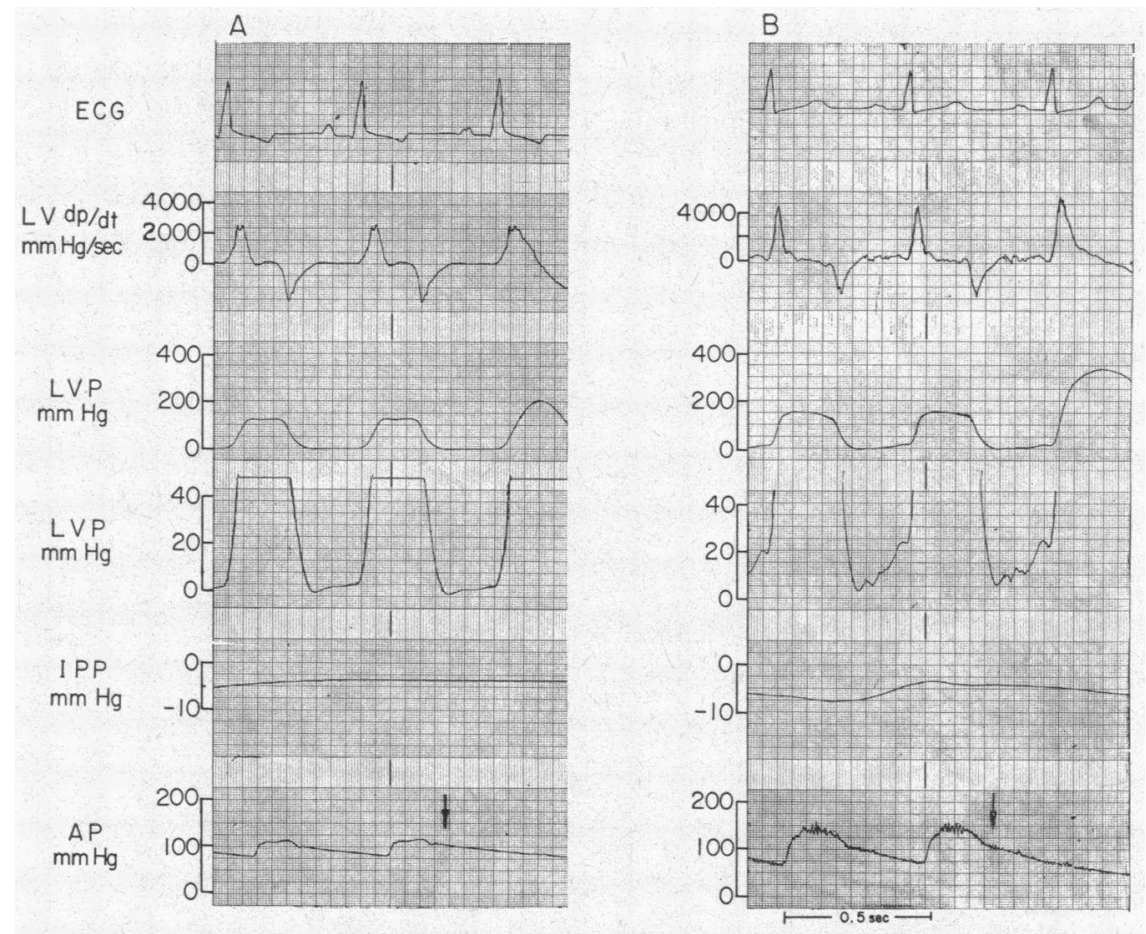

FIGURE 1 Recordings from a normal dog (panel A) and a dog with an aorto-caval fistula (panel B). Representative recordings made at spontaneous heart rate and ventricular filling pressure. Arrows indicate points at which balloon has been inflated to produce isovolumic contractions. $\mathrm{ECG}=$ electrocardiogram; $\mathrm{LVP}=$ left ventricular pressure; $\mathrm{LV} \mathrm{dp} / \mathrm{dt}=$ rate of change of $\mathrm{LVP}$; IPP $=$ intrapleural pressure ; $A P=$ aortic pressure. 
TABLE I

Initial Hemodynamic

\begin{tabular}{|c|c|c|c|c|}
\hline & $\begin{array}{c}\text { Body } \\
\text { wt }\end{array}$ & $\begin{array}{l}\text { LV } \\
\text { wt }\end{array}$ & $\begin{array}{l}\text { Heart } \\
\text { rate }\end{array}$ & $\begin{array}{c}\text { Aortic } \\
\text { pressure }\end{array}$ \\
\hline & $k g$ & $\mathrm{~g} / \mathrm{kg}$ & beats/min & $m m \mathrm{Hg}$ \\
\hline Normal (15) & $19.3 \pm 2.5$ & $5.25 \pm 0.56$ & $125 \pm 38$ & $133 / 94 \pm 20 / 17$ \\
\hline Aorto-caval fistula (9) & $\begin{array}{c}20.3 \pm 1.7 \\
(23.3 \pm 4.0) \ddagger\end{array}$ & $6.32 \pm 0.70 \S$ & $138 \pm 20$ & $154 / 75 \pm 22 / 17$ \\
\hline Significance of difference, $P$ & $\mathrm{NS}(<0.01) \ddagger$ & $<0.001$ & NS & $<0.02 \|$ \\
\hline
\end{tabular}

* Mean values \pm 1 SD. Aorto-caval fistula group includes two animals without clinical evidence of fluid retention; $\mathrm{LV}=$ left ventricle; $w \mathrm{t}=$ weight $; \mathrm{LVEDP}=$ transmural left ventricular end-diastolic pressure $; \mathrm{EDV}=$ left ventricular end-diastolic volume; $\mathrm{SV} / \mathrm{EDV}=$ stroke volume/end-diastolic volume ratio.

$\ddagger$ Weight at time of experiment. Other weights refer to initial weights at time of preparative surgery.

$\S \mathrm{LV}$ wt referred to initial weight.

|| Systolic pressure higher and diastolic pressure lower in aorto-caval fistula group, both $P<0.02$.

Comparisons of mean values from the two groups of animals were made by the two-tailed Student's $t$ test.

\section{RESULTS}

Seven of the nine animals studied had prominent fluid retention with between 600 and $5100 \mathrm{ml}$ of ascitic fluid, edema most marked in the hind limbs, and increases in body weight averaging $4.6 \mathrm{~kg}$ despite obvious muscle wasting. Three of these dogs also had pleural effusions of up to $500 \mathrm{ml}$ and most exhibited dyspnea. Two of the nine did not have evidence of fluid retention, and in these dogs body weight did not increase from the time of preparative surgery to study.

Fig. 1 shows typical recordings from a normal dog and from a dog with an aorto-caval fistula in which the spontaneous heart rates were approximately equal. Isovolumic contractions were produced by rapidly inflating the ascending aortic
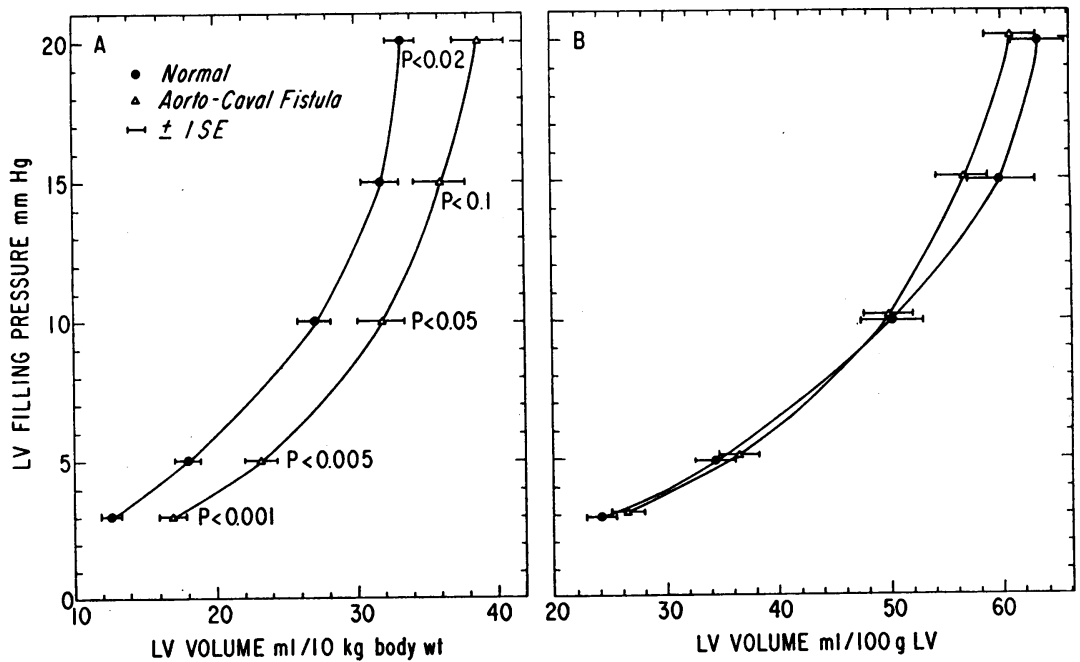

FiguRE 2 Left ventricular pressure-volume curves in normal dogs and in dogs with an aorto-caval fistula. Volume is expressed per kilogram of animal body weight in panel $\mathrm{A}$ and per $100 \mathrm{~g}$ of left ventricle in panel $\mathrm{B}$. Values are mean \pm 1 SE. $P$ values in panel $A$ refer to the significance of the difference between group means. There was no significant difference between the two groups in panel B. 


\begin{tabular}{|c|c|c|c|c|c|}
\hline LVEDP & EDV & $\begin{array}{l}\text { Cardiac } \\
\text { output }\end{array}$ & SV/EDV & $\begin{array}{l}\text { Peak iso- } \\
\text { volumic } \\
\text { pressure }\end{array}$ & $\begin{array}{l}\text { Total iso- } \\
\text { volumic } \\
\text { tension }\end{array}$ \\
\hline$m m \mathrm{Hg}$ & $m l$ & $\begin{array}{c}\text { liter } / \text { min } \\
\text { (ml per min per } k g)\end{array}$ & & $m m \mathrm{Hg}$ & $\mathrm{g} / \mathrm{cm}^{2}$ \\
\hline $7.1 \pm 2.3$ & $40.5 \pm 10.3$ & $\begin{array}{l}2.44 \pm 0.86 \\
(124 \pm 33)\end{array}$ & $0.50 \pm 0.13$ & $251 \pm 55$ & $332 \pm 105$ \\
\hline $27.6 \pm 4.1$ & $77.7 \pm 17.6$ & $\begin{array}{l}6.99 \pm 1.70 \\
(347 \pm 64)\end{array}$ & $0.67 \pm 0.12$ & $307 \pm 23$ & $543 \pm 53$ \\
\hline$<0.001$ & $<0.001$ & $<0.01$ & $<0.01$ & $<0.01$ & $<0.001$ \\
\hline
\end{tabular}

balloon at the arrows. From a transmural left ventricular end-diastolic pressure (LVEDP) of $5.7 \mathrm{~mm} \mathrm{Hg}$ the isovolumic contraction in the normal dog reached a pressure of $210 \mathrm{~mm} \mathrm{Hg}$ and tension $206 \mathrm{~g} / \mathrm{cm}^{2}$ whereas the LVEDP in the dog with an aorto-caval fistula was $26-1 \mathrm{~mm} \mathrm{Hg}$, peak isovolumic pressure $341 \mathrm{~mm} \mathrm{Hg}$, and tension $616 \mathrm{~g} / \mathrm{cm}^{2}$. The mean values in the normal dogs and in the nine dogs with an aorto-caval fistula for body weight, left ventricular (LV) weight, and for resting hemodynamic measurements made before cross transfusion and control of heart rate, are presented in Table I. The hemodynamic measurements in the two dogs without clinical evidence of fluid retention conformed to those of the others in this group. Mean transmural right atrial pressure was measured in five animals, all of which had fluid retention, and these had slightly elevated pressures (average $7.8 \mathrm{~mm} \mathrm{Hg}$ ). The transmural left ventricular end-diastolic pressures (LVEDP) were markedly elevated, ranging from 21.0 to $32.7 \mathrm{~mm} \mathrm{Hg}$ (average, $27.6 \mathrm{~mm} \mathrm{Hg}$ ). The LV weight in Table I is referred to body weight at the time of initial preparative surgery and was significantly greater in the aorto-caval group than in the normal $(P<0.001)$.

Fig. 2 shows mean pressure-volume curves for the left ventricle in each group of animals. For a given filling pressure the LV volume per unit of initial body weight was significantly greater in the aorto-caval group than in the normal; however, $L V$ volume per unit of LV weight was not different in the two groups.

Subsequent results were obtained after cross transfusion and control of heart rate. Since $V_{\max }$ was normal in the two aorto-caval dogs without fluid retention ( 3.3 and $3.0 \mathrm{circ} / \mathrm{sec}$ ), these dogs have been excluded from all subsequent analyses

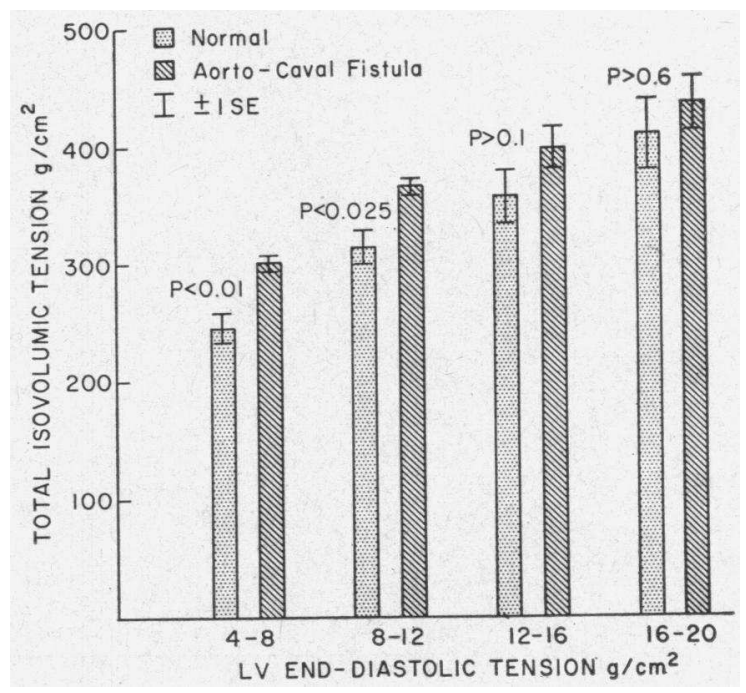

FIGURE 3 Total isovolumic tension in normal dogs and in dogs with an aorto-caval fistula and fluid retention at four levels of left ventricular end-diastolic tension. $P$ values refer to the significance of the difference between means for the two groups. 
lest it be considered that they might have biased the results toward the normal.

Tension-velocity relations derived from isovolumic contractions in the dogs with an aortocaval fistula were qualitatively similar to those in the normal dogs (11), an approximately hyperbolic relation between tension and velocity being estal:lished after $30-40 \mathrm{msec}$ of contraction and continuing until 30-40 msec before peak tension $\left(P_{v}\right)$ was reached. $V_{\max }$, obtained by visual extrapolations of the tension-velocity relations was not o.bviously changed by changing left ventricular filling in individual animals of either group, $\mathrm{V}_{\max }$ averaging $3.0 \pm 0.07(\mathrm{SE}) \mathrm{circ} / \mathrm{sec}$ in the 15 normal and $2.9 \pm 0.13 \mathrm{circ} / \mathrm{sec}$ in the seven aortocaval dogs. In only one of the latter was $\mathrm{V}_{\max }$ below the normal range of 2.7 to $3.5 \mathrm{circ} / \mathrm{sec}$; this animal with a $\mathrm{V}_{\max }$ of $2.2 \mathrm{circ} / \mathrm{sec}$ had the most extreme evidence of fluid retention, its weight had increased from 19.5 to $27.3 \mathrm{~kg}$ and 4 liters of ascitic fluid and $500 \mathrm{ml}$ of pleural fluid were present. The time to peak pressure and tension averaged $139 \pm 3$ ( $\mathrm{SE}$ ) msec in the normal and $151 \pm 6 \mathrm{msec}$ in the aorto-caval group, a

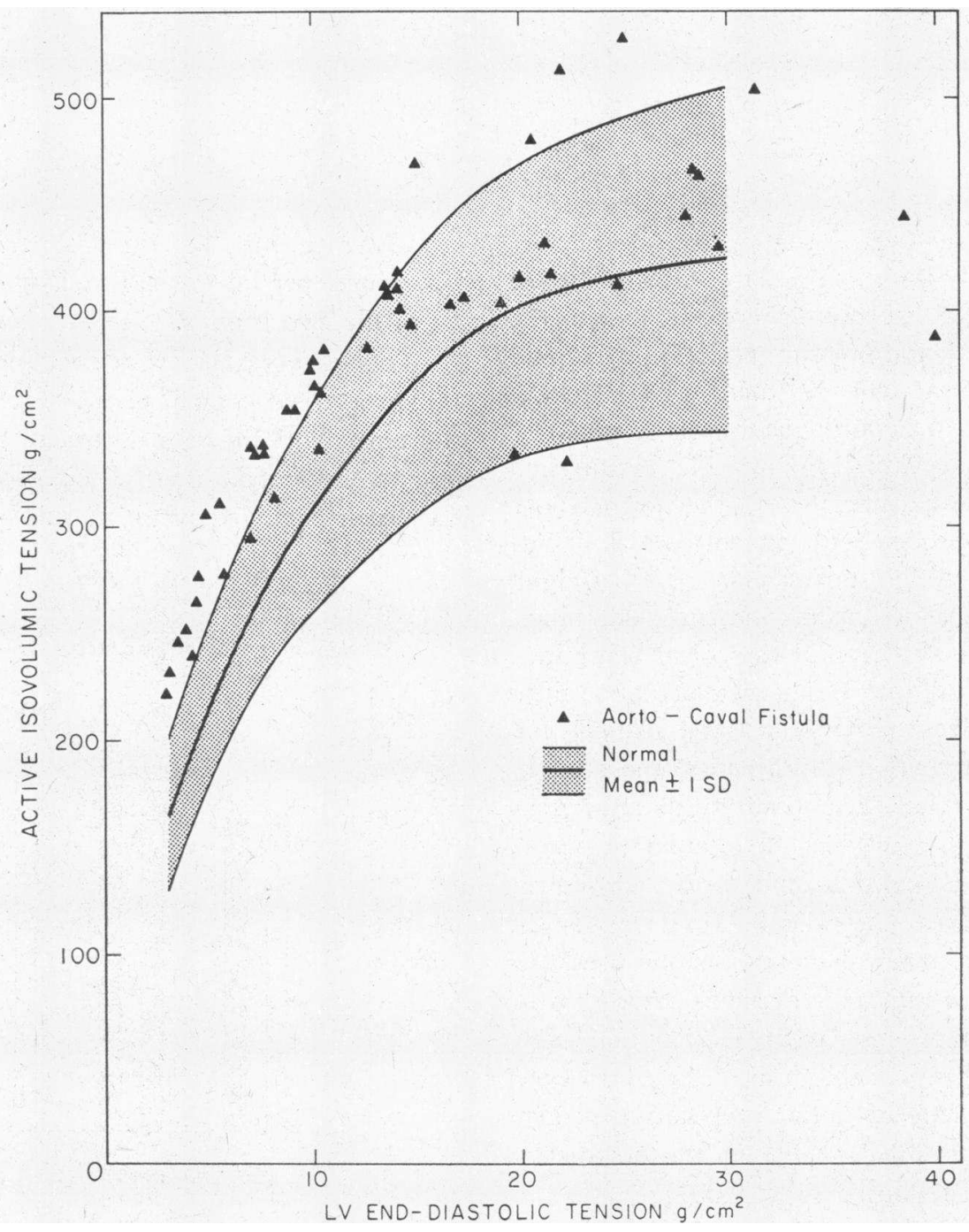

FIGURE 4 Active isovolumic tension plotted against left ventricular end-diastolic tension. Individual observations in seven dogs with an aorto-caval fistula and fluid retention, and the normal mean curve \pm 1 sD derived from 89 observations in 15 normal dogs are shown. 

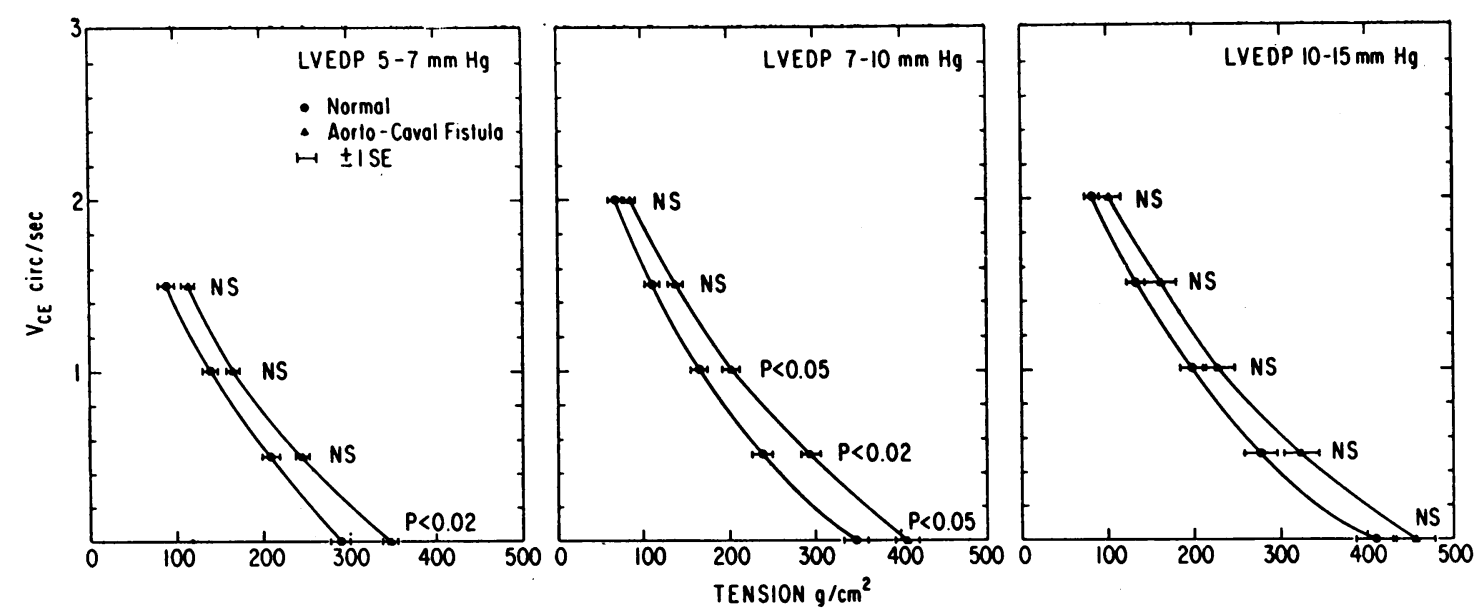

FIGURE 5 Mean active tension-velocity relations, in $n$ ormal dogs and in dogs with an aorto-caval fistula and fluid retention, at each of three levels of transmural left ventricular end-diastolic pressure (LVEDP). $P$ values refer to the significance of the differences between mea:s in the two groups of animals.

difference not quite significant at the 0.05 level $(\mathrm{t}=2.070, \mathrm{n}=20)$.

Increasing left ventricular end-diastolic pressure increased $\mathrm{P}_{\mathrm{o}}$ in contractions from both groups of animals, and further comparisons of $\mathrm{P}_{\mathrm{o}}$ and tension-velocity relations were made with observations grouped both according to LVEDP and according to end-diastolic tension. Fig. 3 shows that at low levels of end-diastolic tension, $\mathrm{P}_{\mathrm{o}}$ was higher in the aorto-caval group than in the normal group, but there was no significant difference at higher levels of ventricular filling. A similar result is apparent from Fig. 4, in which active isovolumic tension is plotted against end-diastolic tension for all individual observations in the aorto-caval dogs and a mean curve $\pm 1 \mathrm{SD}$ is plotted for the observations in the normal dogs, and also can be seen in Fig. 5, in which observations are grouped according to LVEDP.

In Fig. 5 the mean tension-velocity relations, obtained by calculating mean tensions at the selected velocities indicated, are shown for the normal and aorto-caval animals for the LVEDP groups $5-7,7-10$, and $10-15 \mathrm{~mm} \mathrm{Hg}$. The curves in the dogs with aorto-caval fistulas tend to lie to the right of the normal, but the differences were significant only at the lower LVEDP's, and in that part of the curves at which tension is high. Similar relations were apparent when the observations were grouped according to end-diastolic tension.

\section{DISCUSSION}

The general hemodynamic findings, consisting of a high cardiac output, elevated left ventricular end-diastolic pressure (LVEDP), and augmented aortic pulse pressure in the dogs with an aortocaval fistula, conform to those previously found in the presence of a large arteriovenous fistula in the experimental animal (6-10) and in man $(1-4)$. The high pressure and tension development by isovolumic contractions originating from the high LVEDP in the dogs with an aorto-caval fistula (Fig. 1) and the higher ejected fraction, $\mathrm{SV} / \mathrm{EDV}$, in ejecting beats, also are not unexpected since both isovolumic pressure development (11) and muscle fiber shortening, and hence SV/ EDV (16), are influenced by ventricular filling. The most striking of the present results, however, is that in only one of the seven animals with an aorto-caval fistula, circulatory congestion, and marked fluid retention, was left ventricular contractility depressed below the normal range, as judged by tension-velocity relations, $\mathrm{V}_{\max }$, and isovolumic tension development. The mean tension-velocity relations of these seven animals actually lay somewhat to the right of the normal relations at lower filling pressures in that peak insovolumic tension $\left(\mathrm{P}_{0}\right)$ tended to be a little higher than normal. Tension was derived in units of stress, so that the higher $\mathrm{P}_{0}$ cannot be explained simply on the basis of a greater muscle mass.

The importance of comparing tension-velocity 
relations and $P_{o}$ at similar levels of LVEDP or of end-diastolic tension (stress) in the intact ventricle has been emphasized in recent communications (11 and footnote 8) and the results were the same with either method of standardization. It could be, however, that even end-diastolic tension is not an entirely adequate normalizing factor under the present conditions, since if stress relaxation occurred in elements parallel to the contractile elements, then a dissociation could occur between end-diastolic stress and end-diastolic sarcomere length, the ultrastructural determinant of contractile force (17). Another factor which may have been partly responsible for the slightly higher $\mathrm{P}_{\mathrm{o}}$ 's in the dogs with an aorto-caval fistula was the tendency for isovolumic contractions in these dogs to have a greater time to peak pressure and, hence, presumably greater duration of active state (18) than contractions in the normal dogs. Either or both of the above factors could explain the slightly higher $\mathrm{P}_{\mathrm{o}}$ in some experiments in which $\mathrm{V}_{\max }$ was normal.

The contractile state of the left ventricle subjected to a large chronic flow load produced ex. perimentally in the dog has not been well documented previously. Ferguson, Gregg, and Shadle (8) found that the maximum cardiac output attainable by transfusing dogs that had an aortocaval fistula was greater than that reached in normal dogs, although the maximum stroke work was less since the aortic pressure did not increase as much with transfusion in the dogs with an aorto-caval fistula as in the normal animals. Thus, whereas these findings suggested that left ventricular function was not depressed, no firm conclusions could be drawn. It is apparent from the present study that elevation of left ventricular enddiastolic pressure by a large flow load is not indicative of left ventricular myocardial failure as is sometimes implied (19). Even in the presence of marked circulatory congestion and fluid retention, left ventricular contractility was usually normal in the dogs with an aorto-caval fistula; in only one animal with the severest degree of congestion were the left ventricular tension-velocity relation and $\mathrm{V}_{\max }$ depressed.

8 Taylor, R. R., J. W. Covell, and J. Ross, Jr. Influence of the thyroid state on left ventricular tension-velocity relations in the intact, sedated dog. Submitted for publication.
That the present methodology is capable of detecting and characterizing a depression of left ventricular contractile state is indicated by the depression of the left ventricular tension-velocity relation and $V_{\max }$ recently found in the intact hypothyroid dog (without evidence of circulatory congestion) and the elevation of the tensionvelocity relation and $\mathrm{V}_{\max }$ found in the hyperthyroid dog. ${ }^{8}$ It also has been shown in acute experiments that this approach provides a more sensitive indication of alterations in contractile state than does the ventricular function curve (20). The usual finding in the present study of normal contractility in the dog ventricle subjected to a large chronic flow load contrasts with the depression of contractile state, considered to occur in the dog's left ventricle subjected to a chronic pressure load, as indicated by a lower maximum force development per unit mass of the left ventricle in response to aortic occlusion in the chronically loaded ventricle compared with that in the normal (21). In the cat's right ventricle subjected to a chronic pressure load, depression of the tension-velocity relation and $\mathrm{V}_{\max }$ have been documented both in vitro and in vivo $(22,23)$.

Despite normal function per unit of left ventricular muscle, and despite the additional compensatory mechanism of ventricular hypertrophy evidenced by the increase in ventricular weight relative to body weight, edema and ascites were present in seven of the nine dogs with an aortocaval fistula studied. The mechanisms of fluid retention in the dog with an aorto-caval fistula have been well documented by previous workers. A large systemic arteriovenous shunt, under either acute or chronic conditions, leads to a fall in renal blood flow $(10,24)$, as well as reductions in flow to other organs and the limbs $(7,9)$. Renal plasma flow and glomerular filtration rate are decreased, and there is an increased production of aldosterone (1), presumably mediated by the renin-angiotensin system (25). This response appears related to some function of renal perfusion (10) and/or to pressure in other parts of the arterial tree (26). Sodium and water retention are considered to result from the increased aldosterone production, whereas the changes in renal plasma flow and glomerular filtration may or may not be important $(10,26)$. It should be noted that these mechanisms 
for fluid retention are primarily dependent upon changes on the arterial side of the circulation.

Not only is there little evidence for mechanisms of fluid retention primarily dependent upon right heart or systemic venous distension, but right atrial distension, in fact, leads to a decrease in aldosterone production (27) ; moreover, the infrarenal aorto-caval shunt was associated with only modest elevations of right atrial pressure in this study, as in a previous investigation by Davis, Urquhart, Higgins, Rubin, and Hartroft (10). The production of isolated tricuspid regurgitation in the dog, leading to elevations of right atrial pressure of approximately the same magnitude, does not lead to ascites and edema although the response to a salt load is abnormal (28); the fluid retention which results from the combination of pulmonary stenosis and tricuspid regurgitation has been considered to be a function of changes on the arterial side of the circulation (25). Elevation of renal venous pressure would not appear to be an important determinant of the fluid retention, since sustained elevation of renal venous pressure by partial constriction of the inferior vena cava does not lead to sustained changes in renal blood flow, glomerular filtration rate, or sodium excretion (29).

The concept that congestive circulatory failure and cardiac muscle failure are not synonymous under clinical circumstances in man is well described $(30,31)$. However, the cardiac lesions leading to fluid retention in the presence of normal myocardial function usually have been confined to mechanical abnormalities such as valvular or constrictive lesions, and adequate techniques for the assessment of myocardial function in the intact animal have not been available. The present study, demonstrating normal left ventricular function in the presence of a large volume load, elevated left ventricular end-diastolic pressure, and circulatory congestion emphasizes that mechanisms for fluid retention may be brought into play by a disparity between the requirements for blood flow and the heart's ability to meet those requirements. Whereas in many situations such a disparity results from depression of myocardial function in the presence of a normal circulatory load, in the present study the disparity apparently resulted from the inability of the normal heart to maintain pressure and flow in the peripheral circulation in the face of a large runoff through the fistula.

\section{REFERENCES}

1. Cohen, S. M., O. G. Edholm, S. Howarth, J. McMichael, and E. P. Sharpey-Schafer. 1948. Cardiac output and peripheral blood flow in arteriovenous aneurysm. Clin. Sci. 7: 35.

2. Warren, J. V., J. L. Nickerson, and D. C. Elkin. 1951. The cardiac output in patients with arteriovenous fistulas. J. Clin. Invest. 30: 210.

3. Epstein, F. H., O. W. Shadle, T. B. Ferguson, and M. E. McDowell. 1953. Cardiac output and intracardiac pressures in patients with arteriovenous fistulas. J. Clin. Invest. 32: 543.

4. Muenster, J. J., J. S. Graettinger, and J. A. Campbell. 1959. Correlation of clinical and hemodynamic findings in patients with systemic arteriovenous fistulas. Circulation. 20: 1079.

5. Warren, J. V., D. C. Elkin, and J. L. Nickerson. 1951. The blood volume in patients with arteriovenous fistulas. J. Clin. Invest. 30: 220.

6. Harrison, T. R., W. Dock, and E. Holman. 1924. Experimental studies in arterio-venous fistulae: cardiac output. Heart. 11: 337.

7. Van Loo, A., and E. C. Heringman. 1949. Circulatory changes in the dog produced by acute arteriovenous fistula. Am. J. Physiol. 158: 103.

8. Ferguson, T. B., D. E. Gregg, and O. W. Shadle. 1954. Effect of blood and saline infusion on cardiac performance in normal dogs and dogs with arteriovenous fistulas. Circulation Res. 2: 565.

9. Frank, C. W., H. H. Wang, J. Lammerant, R. Miller, and R. Wegria. 1955. An experimental study of the immediate hemodynamic adjustments to acute arteriovenous fistulae of various sizes. J. Clin. Invest. 34: 722.

10. Davis, J. O., J. Urquhart, J. T. Higgins, Jr., E. C. Rubin, and P. M. Hartroft. 1964. Hypersecretion of aldosterone in dogs with a chronic aortic-caval fistula and high output heart failure. Circulation Res. 14: 471.

11. Taylor, R. R., J. W. Covell, and J. Ross, Jr. 1967. Left ventricular force-velocity relations in the intact, unanesthetized dog. Circulation Res. 21: 99.

12. Taylor, R. R., J. W. Covell, E. H. Sonnenblick, and J. Ross, Jr. 1967. Dependence of ventricular distensibility on filling of the opposite ventricle. Am. J. Physiol. 213: 711.

13. Forwand, S. A., K. M. McIntyre, J. G. Lipana, and H. J. Levine. 1966. Active stiffness of the intact canine left ventricle with observations on the effect of acute and chronic myocardial infarction. Circulation Res. 19: 970.

14. Covell, J. W., R. R. Taylor, and J. Ross, Jr. 1967. Series elasticity in the intact left ventricle determined by a quick release technique. Federation Proc. 26: 663 .

15. Sonnenblick, E. H. 1964. Series elastic and contractile elements in heart muscle: changes in muscle length. Am. J. Physiol. 207 : 1330. 
16. Taylor, R. R., H. E. Cingolani, and R. H. McDonald, Jr. 1966. Relationships between left ventricular volume, ejected fraction and wall stress. Am. J. Phy'siol. $211: 674$.

17. Sonnenblick, E. H., D. Spiro, and H. M. Spotnitz. 1964. The ultrastructural basis of Starling's law of the heart. The role of the sarcomere in determining ventricular size and stroke volume $A m$. Heart J. 68: 336.

18. Sonnenblick, E. H. 1967. Active state in heart muscle. Its delayed onset and modification by inotropic agents. J. Gen. Physiol. 50: 661.

19. Friedberg, C. K., R. P. Lasser, D. F. Allen, S. E. Furst, and G. E. Gabor. 1964. Production of chronic elevation of left ventricular end diastolic pressure in dogs : hemodynamic and renal studies. Circulation Res. $15: 1$.

20. Covell, J. W., J. Ross, Jr., E. H. Sonnenblick, and E. Braunwald. 1966. Comparison of the forcevelocity relation and the ventricular function curves as measures of the contractile state of the intact heart. Circulation Res. 19: 364.

21. Meerson, F. Z. 1965. A mechanism of hypertrophy and wear of the myocardium. Am. J. Cardiol. 15: 755.

22. Spann, J. F., Jr., R. A. Buccino, E. H. Sonnenblick, and E. Braunwald. 1967. Contractile state of cardiac muscle obtained from cats with experimentally produced ventricular hypertrophy and heart failure. Circulation Res. 21 : 341.

23. Spann, J. F., Jr., J. W. Covell, D. L. Eckberg, E. H. Sonnenblick, J. Ross, Jr., and E. Braunwald. 1967. Myocardial contractile state in hypertrophy and con- gestive failure, studied in the intact heart and the isolated muscle. J. Clin. Invest. 46: 1118. (Abstr.)

24. Hilton, J. G., D. M. Kanter, D. R. Hays, E. H. Bowen, J. R. Golub, J. H. Keating, and R. Wegria 1955. The effect of acute arteriovenous fistula on renal functions. J. Clin. Invest. 34: 732.

25. Urquhart, J., J. O. Davis, and J. T. Higgins. 1964. Stimulation of spontaneous secondary hyperaldosteronism by intravenous infusion of angiotensin II in dogs with an arteriovenous fistula. J. Clin. Invest. 43: 1355 .

26. Bortter, F. C., and D. S. Gann. 1960. On the hemodynamic regulation of the secretion of aldosterone. Circulation. 21: 1016.

27. Anderson, C. H., M. McCally, and G. L. Farrell. 1959. The effects of atrial stretch on aldosterone secretion. Endocrinology. 64: 202.

28. Barger, A. C., F. E. Yates, and A. M. Rudolph. 1961. Renal hemodynamics and sodium excretion in dogs with graded valvular damage, and in congestive failure. Am. J. Physiol. 200: 601 .

29. Hwang, W., L. C. Akman, A. J. Miller, E. N. Silber, J. Stamler, and L. N. Katz. 1950. Effects of sustained elevation of renal venous pressures on sodium excretion in unanesthetized dog. Am. J. Physiol. 162: 649.

30. Eichna, L. W., S. J. Farber, A. R. Berger, B. Rader, W. W. Smith, and R. E. Albert. 1954. Non-cardiac circulatory congestion simulating congestive heart failure. Trans. Am. Acad. Physicians. 67: 72.

31. Katz, L. N., H. Feinberg, and A. B. Shaffer. 1960. Hemodynamic aspects of congestive heart failure. Circulation. 21: 95. 